\title{
Factors associated with experimentation of (1) camatax electronic cigarettes among Parisian teenagers in 2013
}

Bertrand Dautzenberg ${ }^{1,2,3,5^{*}}$, Ivan Berlin ${ }^{2,3}$, Marie-Laure Tanguy ${ }^{2}$, Nicole Rieu ${ }^{4}$ and Pierre Birkui ${ }^{1}$

\begin{abstract}
Background: Electronic cigarettes (e-cig.) became widely used among adults. Data are insufficient about e-cig. experimentation among youth.

Methods: To assess prevalence of e-cig. experimentation and associated factors among the 12 to 19 years old we analyse a cross sectional school based survey in the city of Paris, France in 2013 on a randomly selected sample of $2 \%$ of schoolchildren ( $n=3279$ ). Self-report questionnaire include demographic, individual and family smoking characteristics and questions about e-cig: "Have you ever used an e-cigarette?"- "Did you use e-cigarette in the last 30 days?"-"Did you try e-cigarette as a first tobacco product?"

Results: In 2013, $17.9 \%$ (564) schoolchildren reported having experienced the e-cig (boys: $19.0 \%$, girls: $16.8 \%$ ) compared to $9.8 \%$ in 2012. Experimentation rate increases from $5 \%$ among the 12 to $30 \%$ among the 16 -year-old. E-cig. experimentation was significantly associated with 11 parameters including : age >15 years (OR: 0.66 (IC95 \% = 0.46-0.94)); smoking 10 cigarettes or more $(\mathrm{OR}=5.67($ IC95 $\%=3.11-10.34))$, best friends and siblings smoker (OR = $1.54(\mathrm{IC} 95 \%=1.11-2.14))$ and $(\mathrm{OR}=1.88(\mathrm{IC} 95 \%=1.41-2.52))$; experimentation of shisha (OR $=2.60$ $($ IC95 \% = 1.75-3.86)), cannabis use (OR=1.90 (IC95 \% = 1.32-2.72)); having two parents who forbid smoking $(\mathrm{OR}=2.32(\mathrm{IC} 95 \%=1.63-3.30)$ ). Only $5.6 \%$ of the study population (and $32.5 \%$ of e-cig. experimenters $(183 / 564))$ have used it in the last 30 days; $1.7 \%$ of the study population and $10.0 \%$ of e-cig. experimenters were non-smokers (56/564).

Conclusions: Rate of e-cig. experimentation among schoolchildren increased by $8.1 \%$ in 1 year. Non-smoking youth may use e-cig. Prospective studies are urgently needed to assess the evolution of e-cig. use both among smoking and non-smoking youth.
\end{abstract}

Keywords: Electronic cigarette, Teenagers, Survey

\section{Background}

Electronic cigarettes (e-cig) are a new product that has reached some maturity; currently available devices seem to be more secure than those available several years ago [1]. E-cig. appear to be less toxic than conventional cigarettes if used by a smoker [2, 3]. Only some public health advisors and physicians are neutral, some argue for a prohibition or severe restriction of the e-cig. use $[4,5]$ when others encourage adult smokers to switch from tobacco to e-cig. $[6,7]$, but

\footnotetext{
*Correspondence: bdautz@gmail.com

'Paris Sans Tabac (PST), Paris, France

${ }^{2}$ University Hospital Pitié Salpêtrière-Charles Foix (APHP), Paris, France

Full list of author information is available at the end of the article
}

all agree to keep as low as possible the use of e-cig by teenagers [8].

E-cig. are widely considered as a product that may help smokers quit, but, as of today, there is only little evidence supporting this [9]. Moreover, there is a concern that long term use may induce initiation of conventional cigarette or other types of tobacco use among youth. Although the long-term effect of e-cig' use among youth can only be assessed by prospective studies, there is an urgent need to generate knowledge even by crosssectional studies about factors associated with its use to accumulate as quickly as possible new data.

Paris Sans Tabac (PST), a non-profit foundation aiming to reduce prevalence of tobacco in Paris, conducts 
yearly surveys of schoolchildren aged 12 to 19 years. A question about e-cig. experimentation was introduced in 2012 [10] and in the 2013 survey two more questions have been added. We report here about factors associated with the experimentation of e-cig. among Parisian schoolchildren.

\section{Methods}

\section{The PST survey}

From 1991 on a cross-sectional anonymised survey has been conducted every year among $2 \%$ of schoolchildren randomly selected by class clusters from the list of classes (4. 842 public and 2424 private) provided by Paris' school authorities with quotas by class level from both private and public schools to provide a representative sample of the 188000 schoolchildren of the City of Paris.

The one page self-report questionnaire is distributed and collected with the help and explicit agreement of school authorities of the City of Paris. Every year, one of the usual teachers, with or without the help of the school nurse, distributes and collects the questionnaire in the designated classes. In 2012 the following question was added to the standard questions: "Have you ever used an e-cigarette?" In 2013 two further questions were added: "Did you use e-cigarette in the last 30 days?" and "Did you try e-cigarette as a first tobacco product?"

The standard questionnaire contained the following items: age, gender, smoking status (smoker, former smoker, non-smoker) of the father, mother, brothers, sisters and best friend; prohibition of tobacco use by one or two parents; ever use of tobacco; age of the first cigarette smoked, current smoking status (daily smoker, occasional smoker, former smoker, non-smoker); experimentation with shisha (hookah) and with cannabis; amount of use of alcohol last month; intention to quit tobacco. The classes' identification provides information about studying in a private or a public school which allows approximating by the City's website the mean income/inhabitant of the school district. Upon completion, the questionnaires are scanned and analysed with the Neoptec $^{\bullet}$ software (Marseille, France).

\section{Missing data's}

A total of 3279 questionnaires, who have no missing data on age and smoking status was are included in the study. The missing date are less $5 \%$ for most of questions: For the question on experimentation of e-cig $3.9 \%$ of answers are missing $(n=128)$. For the multivariate analysis $31.5 \%$ of questionnaires had at least a missing value for one of the 9 parameters included in the analysis, so the multivariate analysis has been performed on $69.5 \%$ of the whole population (2 279).

\section{Data analysis}

Data are reported as frequencies (percent) and number. Potential associations with experimentation of e-cig. were studied using chi-square tests. Variables that were significant in univariate analyses at $p \leq 0.05$ were included in a stepwise logistic regression model. The alpha level was set at 0.05 .

All analyses were performed with the SAS software version 8.2 (SAS Institute ${ }^{\circ}$, Cary, NC).

\section{Results}

\section{Study population}

A total of 3279 schoolchildren completed the questionnaire. Their age ranged from 12 to 19 years. Forty eight percent of the sample was male. In this population the rate of non-smokers is $72.4 \%$, of daily or occasional smokers is $26.1 \%$ and the rate of former smokers $1.6 \%$.

\section{Experimentation of electronic cigarette}

In 2013, 564 schoolchildren reported having experimented at least once the e-cig., 2587 had not and 128 answers were missing. The rate of e-cig. experimenters is $17.9 \%$ among the 3151 respondents $(17.2 \%$ of the whole population). The e-cig. experimentation rate was $16.8 \%$ among girls and $19.0 \%$ among boys. The e-cig. experimentation rate starts to increase among the 13 years old and reaches $30 \%$ among the 16 years old (Fig. 1). The rate of experimentation of e-cig. is $7.1 \%$ in non-smokers, $37.3 \%$ in former smokers, $38.7 \%$ in occasional smokers and $63.0 \%$ in daily smokers.

\section{Factors associated with experimentation of electronic cigarettes}

In univariate analyses the following variables were significantly associated with e-cig. experimentation and were included in the multivariate analysis: age, gender, smoking status (smoker, former smoker, non-smoker) of the father, mother, brother, sister and best friend; prohibition of tobacco use by one or two parents; ever use of tobacco, current smoking status (smoker, former smoker, non-smoker), experimentation of shisha, cannabis; use of alcohol in the last month, experience of binge drinking; studying in a private or a public school, mean income per inhabitant of the school area (Table 1). Two variables: intention to quit tobacco and age of the first cigarette were not included into the multivariate analysis because of no significant association with e-cig. experimentation.

\section{Multivariate analysis}

The multivariate analysis was run with 2279 questionnaires $(69.5 \%$ of the initial sample) because of missing data of at least one variable included in the model.

The higher determinants of e-cig. experimentation use were smoking 10 cigarettes or more $(\mathrm{OR}=5.67$ (IC95 \% = 


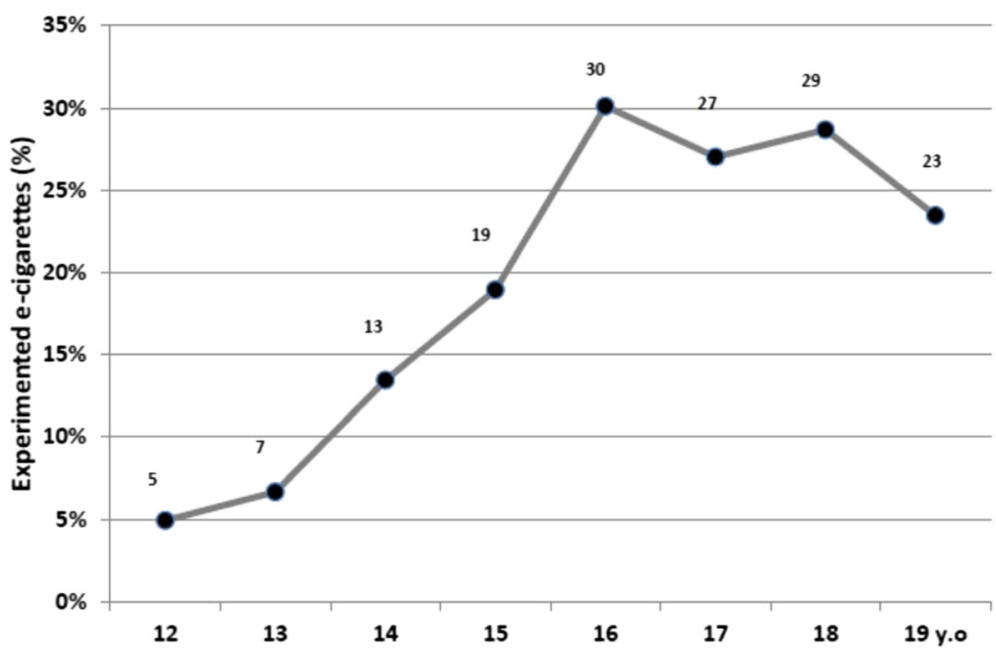

Fig. 1 Electronic cigarette experimentation rate by age in 2013 among 12-19 years old Paris schoolchildren

3.11-10.34)) and ever smoked a cigarette $\mathrm{OR}=4.46$ $($ IC95 \% $=2.81-7.09))$ but the likelihood of electronic cigarette experimentation is also associated with an age less than 15 years, with the current smoking status of the best friend and sibling; with the use of conventional cigarettes, shisha and cannabis, with the prohibition to smoke by at least one of the parents and being in a private school (Table 2).

Non-smokers who experiment electronic cigarette

Among the non-smoking schoolchildren, $2.3 \%$ of nonsmokers and $9.9 \%$ of e-cig. experimenters reported

Table 1 Mains factors associated to experimentation of electronic cigarette in the univariate analysis of the 2013 adolescent study in Paris

\begin{tabular}{|c|c|c|c|c|}
\hline Effect & $n$ & Non experimentation e-cig-(\%) & Experimentation e-cig. (\%) & $p$ \\
\hline Gender $=$ male & 3110 & $47.0 \%$ & $51.0 \%$ & 0.11 \\
\hline Age $12-14$ years & 3151 & $48.9 \%$ & $21.3 \%$ & $<0.0001$ \\
\hline Ager $15-17$ years & & $29.2 \%$ & $44.7 \%$ & \\
\hline Age $>17$ years & & $21.9 \%$ & $34.0 \%$ & \\
\hline Ever cigarettes smoker & 3078 & $31.8 \%$ & $91.0 \%$ & $<0.0001$ \\
\hline Smoking status: non-smoker & 3081 & $84.9 \%$ & $28.1 \%$ & $<0.0001$ \\
\hline Smoking status: former smoker & & $1.1 \%$ & $3.2 \%$ & \\
\hline Smoking status: occasional smoker & & $8.9 \%$ & $27.1 \%$ & \\
\hline Smoking status: daily smoker & & $5.1 \%$ & $41 . \%$ & \\
\hline Ever shisha use & 3126 & $27.7 \%$ & $81.7 \%$ & $<0.0001$ \\
\hline Father smoke & 3055 & $27.7 \%$ & $35 . \%$ & $<0.0001$ \\
\hline Mother smoke & 3099 & $20.3 \%$ & $31.7 \%$ & $<0.0001$ \\
\hline Brothers and sisters smoke & 2929 & $19.0 \%$ & $45.7 \%$ & $<0.0001$ \\
\hline Best friend smoke & 2989 & $17.2 \%$ & $57.9 \%$ & $<0.0001$ \\
\hline Non agreement of parents on the prohibition to smoke & 3048 & $6.0 \%$ & $11.7 \%$ & $<0.0001$ \\
\hline Any alcohol las month & 3070 & $37.3 \%$ & $78.5 \%$ & $<0.0001$ \\
\hline More 4 glasses of alcohol in a day 4 times or more & 2341 & $16.1 \%$ & $47.2 \%$ & $<0.0001$ \\
\hline Cannabis experimentation & 2891 & $88.7 \%$ & $41.8 \%$ & $<0.0001$ \\
\hline Private school & 3153 & $34.8 \%$ & $47.3 \%$ & $<0.0001$ \\
\hline Mean income per inhabitant in the school area $>49 \mathrm{~K} €$ & 3151 & $22.8 \%$ & $31.9 \%$ & $<0.0001$ \\
\hline
\end{tabular}


Table 2 Factors associated to experimentation of electronic cigarette in the multivariate analysis in a 2013 adolescent survey Paris

\begin{tabular}{|c|c|c|c|c|}
\hline \multirow{2}{*}{$\frac{\text { Effect }}{\text { Age }\left(>15 \text { vs } \leq 15^{\mathrm{a}}\right)}$} & \multirow{2}{*}{$\frac{O . R}{0.66}$} & \multicolumn{2}{|c|}{$95 \%$ Wald confidence limits } & \multirow{2}{*}{$\frac{P \text { value }}{0.0217}$} \\
\hline & & 0.46 & 0.94 & \\
\hline Smoking status of best friend (smoker versus non-smoker or ex-smoker ${ }^{\mathrm{a}}$ ) & 1.54 & 1.11 & 2.14 & 0.0089 \\
\hline Smoking status brother (smoker versus non-smoker or ex-smoker or only child ${ }^{\mathrm{a}}$ ) & 1.88 & 1.41 & 2.52 & $<.0001$ \\
\hline Ever smoked a cigarette versus no ${ }^{a}$ & 4.46 & 2.81 & 7.09 & $<.0001$ \\
\hline Ever smoked a shisha versus no ${ }^{a}$ & 2.60 & 1.75 & 3.86 & $<.0001$ \\
\hline Cannabis use versus no ${ }^{a}$ & 1.90 & 1.32 & 2.72 & 0.0005 \\
\hline \multicolumn{5}{|l|}{ Smoking status: } \\
\hline \multicolumn{5}{|l|}{ - No smoking ${ }^{a}$} \\
\hline - Smoking less than 10 cigarettes & 2.28 & 1.57 & 3.29 & $<.0001$ \\
\hline - Smoking 10 cigarettes or more & 5.67 & 3.11 & 10.34 & $<.0001$ \\
\hline Private school (vs. public school ${ }^{a}$ ) & 0.66 & 0.50 & 0.87 & 0.0035 \\
\hline \multicolumn{5}{|l|}{ Parental message of prohibition to smoke: } \\
\hline \multicolumn{5}{|l|}{ - No prohibition ${ }^{a}$} \\
\hline - Prohibition of one parent & 1.84 & 1.08 & 3.12 & 0.0243 \\
\hline - Prohibition of two & 2.32 & 1.63 & 3.30 & $<.0001$ \\
\hline
\end{tabular}

OR odds ratio

${ }^{\mathrm{a}}=$ Reference

having experimented e-cig. (56/2 374). A total of $1.7 \%$ of the study population were non-smokers and e-cig. experimenters (56/564). Among non-smokers who experiment e-cig. 36/56 were male and 45/56 had at least one parent prohibit to smoke. Non-smoker e-cig. experimenters were younger (mean: 15.5 years) than smokers who had experimented e-cig (mean $=17.1$ years).

\section{Electronic cigarette as the first product experimented}

Data on first experimentation of tobacco or tobacco related products were available for 383 schoolchildren. Twelve children (3.1\%) reported e-cig. as the first product used; $64.8 \%$ (248) started smoking by standard cigarettes, $7.3 \%$ (28) by roll your own tobacco, $8.9 \%$ (34) by perfumed cigarette; $12.8 \%$ (49) by using shisha and $3.1 \%$ (12) reported having started to smoke by cigars or other tobacco products.

\section{Use of electronic cigarette in the last 30 days among experimenters of electronic cigarette}

Of the 564 schoolchildren who reported having experimented e-cig., 128 provided no answer on recent use but 183/564 experimenters used it during the last 30 days ( $5.6 \%$ of the study population).

A total of 114/128 experimenter schoolchildren who provided no answer on recent use of tobacco or tobacco related products are non-smokers of occasional smokers (Table 3).

\section{Discussion}

The survey identified several factors significantly associated with e-cig. experimentation among Parisian schoolchildren aged 12 to 19 years. E-cig. experimentation was associated with older age, smoking of a best friend or a brother, smoking of conventional cigarettes or shisha,

Table 3 Use electronic cigarette during the last 30 days among the 564 experimenters of electronic cigarette according to their smoking status

\begin{tabular}{llllll}
\hline & $\begin{array}{l}\text { E-cig. use in the } \\
\text { last 30 days }\end{array}$ & $\begin{array}{l}\text { Non-responder last } \\
30 \text { days }\end{array}$ & $\begin{array}{l}\text { No e-cig. use in the } \\
\text { last 30 days }\end{array}$ & $\begin{array}{l}\text { Percent of responders using } \\
\text { e-cig. last 30 days }\end{array}$ & $\begin{array}{l}\text { Percent of the total sample } \\
\text { using e-cig. last 30 days }^{\mathrm{a}}\end{array}$ \\
\hline Non-smoker & 38 & 87 & 32 & $54.3 \%$ & $24.2 \%$ \\
Occasional smoker & 53 & 27 & 76 & $41.1 \%$ & $34.0 \%$ \\
Ex-smoker & 5 & 9 & 4 & $55.6 \%$ & $27.8 \%$ \\
Daily smoker & 87 & 5 & 141 & $38.2 \%$ & $37.3 \%$ \\
Total & 183 & 128 & 253 & $42.0 \%$ & $32.4 \%$ \\
\hline
\end{tabular}

${ }^{\mathrm{a}}$ The rate of experimenter who had used electronic cigarette during last 30 days is presented as a rate of respondent and of the total study population 
using cannabis and being in a private school. Greater number of current cigarette smoking was dosedependently associated with the likelihood of e-cig. experimentation. Interestingly, and paradoxically, prohibition of smoking by parents was associated with increased likelihood of e-cig. experimentation.

Among those who have experimented e-cig. only $1 / 3$ use it the last 30 days. In the non-smoker sub group who tried e-cig. only $1 / 5$ use it the last 30 days, more the question used in the study on e-cig. use during the last 30 days overestimated the number of daily users, non-assessed in this study.

The fact that near $10 \%$ of the e-cig. experimenters are non-smokers may be an alert but the present data does not allow to conclude that the e-cig. is a gateway to smoking because of the cross-sectional nature of the survey.

\section{Strength and limitations}

Strengths include the random selection of school classes, the relatively large sample size. Limitations include the cross-sectional nature of the study and the reduced representativeness for the whole sample of the multivariate analysis due to missing data. The findings cannot be generalizable to youth of same age in other geographical areas of France, or to other countries or regions than the present sample. As the study is a cross sectional study, association can indicate link between the studied parameters but not causality.

\section{Comparison to the 2012 survey in Parisian schoolchildren}

The 2013 data can be compared historically to the 2012 data [10] because the questions were identical with the exception of those about e-cig. use. In February-March 2012, the e-cig. was a more confidential product which can explain why one of six Parisian schoolchildren, $(16.9 \%)(575 / 3409)$ did not provide answer to the question about e-cig. The response rate to the questions on ecig. dramatically increased between 2012 and 2013: 96.1\% of the schoolchildren provided an answer on e-cig. in February-March 2013, probably because their increased awareness about the product. Similarly, the reported rate of e-cig. experimentation increased respectively from $8.1 \%$ in 2012 to $17.2 \%$ in 2013 of the total sample and from $9.8 \%$ to $17.9 \%$, among the respondents.

\section{Comparison with others studies}

Data about the e-cig. experimentation rate among youth are, as of today, scanty. The Eurobarometer 2012 [11] reports experimentation rate of $5 \%$ in France, $6 \%$ in Europe as of May 2012 among adults; it does not report on e-cig. experimentation rate among youth in France.

In 2010 a Korean survey reported an experimentation rate as low as $0.5 \%$ among students [12]. In 2013 Dutra et al. from the US student survey report an experimentation of e-cig. of $3.1 \%$ in 2011 and $6.5 \%$ in 2012 [13]. In 2011, Goniewicz et al. [14] reported an experimentation rate in Poland of $23.5 \%$ among the 15-19-year-old teenager population and $19.0 \%$ among the 20-24-year-old students.

The 2012 Paris report found an experimenter rate of $8.1 \%$ [10] close to the US report's rate of the same year (6.5\%) [12]. The Paris 2013 survey [10] the rate of experimentation of $17.9 \%$ is close to the rate of experimentation more than 2 years before (2010-2011) observed among Polish adolescents (23.8\%). As in the US student survey 2011-2012 [13], we observed a doubling of experimentation rate between 2012 and 2013.

\section{Use of electronic cigarettes in the last 30 days among experimenters}

We found in the present study that the last 30 days e-cig. use among e-cig. experimenters is $32.4 \%$ ( $42.0 \%$ of responders) similar to that of the Polish study (34.9\%) [14] among the 15-19 years old. Two thirds of e-cig. experimenters do not use it in the last 30 days. Four studies [15-18] concerning adults report a lower rate than reported by our sample with $28-32 \%$ conversion from experimentation to regular (or last 30 days) use. The Eurobarometer 2012 [11] reports a last 30-days use of e-cig. among experimenters of $20 \%$ for France and $17 \%$ for all Europe. According to these data 1/3 to 1/5 of adult e-cig. experimenters had used it during the last 30 days.

\section{Use of electronic cigarette by non-smokers}

In the present study we identified 56 non-smokers who experimented e-cig. ( $9.9 \%$ of e-cig. experimenters and $1.7 \%$ of the study population). These non-smokers were younger than those young smokers who were e-cig. experimenters. Previous studies report only on very small proportions of non-smoker e-cig. experimenters: $1.6 \%$ in a 2011 and $4.4 \%$ in 2012 in the US study [13], $0.1 \%$ in a Korean study [12], 1.4 \% among Polish girls, $3.2 \%$ among Polish boys of 15 to 19 years old (data of 2011) [14]. Our data shows higher non-smokers e-cig. experimentation rate.

This suggests that we urgently need prospective studies to learn whether and to what extent non-smoker e-cig. experimenters become conventional cigarette smokers, chronic e-cig. users or mixed users to elaborate more on place of e-cigarette in promotion or prevention of tobacco use in adolescents.

\section{Conclusions}

E-cigarettes are mainly experiment by schoolchildren who had experienced regular cigarettes, had best friends and sibling smoker. A high tobacco consumption and the prohibition to smoke from the 2 parents is associated to an increased chance to use e-cigarette. 
Rate of e-cig. experimentation among schoolchildren increased by $8.1 \%$ in 1 year from 2012 to 2013 . Less $10 \%$ non-smoking youth may use e-cig.

Prospective studies are urgently needed to assess the evolution of e-cig. use both among smoking and nonsmoking youth.

\section{Competing interests}

The authors had no source of funding, direct or indirect, nor any other connection with the tobacco, electronic cigarette and alcohol industry nor any funding from the pharmaceutical industry.

\section{Authors' contributions}

$\mathrm{BD}$ design the study, conduct the survey, participate to analyse result, drafted the manuscript; IB participate to analyse result; helped to draft the manuscript; MLT participated in the design of the study and performed the statistical analysis NR ; participate to conduct the survey; PB participate to design and conducted the study. All authors read and approved the final manuscript.

\section{Acknowledgment}

We thank the children, teachers, school nurses, school principals, the education authorities of Paris and the Caisse Primaire d'Assurance Maladie de Paris (CPAM) for their administrative support and allowing us the data collection.

\section{Author details}

${ }^{1}$ Paris Sans Tabac (PST), Paris, France. ${ }^{2}$ University Hospital Pitié Salpêtrière-Charles Foix (APHP), Paris, France. ${ }^{3}$ Université Pierre et Marie Curie (upmc), Faculté de médecine, Paris, France. ${ }^{4}$ Rectorat Académie de Paris, Paris, France. ${ }^{5}$ Service de pneumologie - Hôpitaux universitaires Pitié Salpêtrière-Charles Foix, 91 Bd de l'Hôpital, 75651 Paris Cedex 1, France.

Received: 28 September 2014 Accepted: 14 December 2015 Published online: 16 December 2015

\section{References}

1. Rapport et avis d'experts sur la cigarette électronique, OFTA 2013, Paris France http://www.ladocumentationfrancaise.fr/rapports-publics/134000328/ Access on the 30 novembre 2015.

2. Polosa R, Morjaria JB, Caponnetto P, Campagna D, Russo C, Alamo A, et al. Effectiveness and tolerability of electronic cigarette in real-life:a 24-month prospective observational study. Intern Emerg Med. 2014;20:537-46.

3. Burstyn I. Peering through the mist systematic review of what the chemistry of contaminants in electronic cigarettes tells us about health risks. BMC Public Health. 2014;14:18. doi:10.1186/1471-2458-14-18.

4. McNeill A, Brose LS, Calder R, Hitchman SC. E-cigarettes: an evidence update. A report commissioned by Public Health England. https:/www.gov.uk/ government/uploads/system/uploads/attachment_data/file/457102/ Ecigarettes_an_evidence_update_A_report_commissioned_by_Public_Health_ England_FINAL.pdf.

5. Conseil Supérieur de la Santé. Avis 9265 Etat des lieux: cigarette électronique 2015. http://www.health.belgium.be/internet2Prd/groups/ public/@public/@shc/documents/ie2divers/19105017.pdf.

6. WHO - World Health Organization. Electronic nicotine delivery systems reports by WHO. 2014; FCTC/COP/6/Rev1 FCTC Who framework convention on tabacco control. Internet: www.who.int/fctc/publications.

7. Neuberger M. The electronic cigarette: a wolf in sheep's clothing. Wien Klin Wochenschr. 2015;127:385-7.

8. Schneider S, Diehl K. Vaping as a catalyst for smoking? An initial model on the initiation of electronic cigarette use and the transition to tobacco smoking among adolescents. Nicotine Tob Res. 2015. [Epub ahead of print]. http://www.ncbi.nlm.nih.gov/pubmed/26386472.

9. McRobbie H, Bullen C, Hartmann-Boyce J, Hajek P. Electronic cigarettes for smoking cessation and reduction. Cochrane Database Syst Rev. 2014;12: CD010216. doi:10.1002/14651858.CD010216.pub2.

10. Dautzenberg B, Birkui P, Noël M, Dorsett J, Osman M, Dautzenberg MD. Electronic cigarette: a new tobacco product for schoolchildren in Paris. Open J Respir Dis. 2013;3:21-4.
11. European commission. Special Eurobarometer 385 attitudes of Europeans towards tobacco, 2012. http://ec.europa.eu/public_opinion/archives/ebs/ ebs_385_en.pdf Access on the 30 Novembre 2015.

12. Cho JH, Shin E, Moon SS. Electronic-cigarette smoking experience among adolescents. J Adolesc Health. 2011;49:542-674.

13. Dutra LM, Glantz AS. Electronic cigarettes and conventional cigarette use among US adolescents. A cross-sectional study. JAMA pediatrics. 2014;168:610-7.

14. Goniewicz ML, Zielinska-Danch W. Electronic cigarette use among teenagers and young adults in Poland. Pediatrics. 2012;130:e879-85.

15. Sutfin EL, McCoy TP, Morrell HE, Hoeppner BB, Wolfson M. Electronic cigarette use by college students. Drug Alcohol Depend. 2013;131:214-21.

16. Kralikova E, Kubatova S, Truneckova K, Kmetova A, Hajek P. The electronic cigarette:what proportion of smokers has tried it and how many use it regularly? Addiction. 2012;107:1528-9.

17. King BA, Alam S, Promoff G, Arrazola R, Dube SR. Awareness and ever use of electronic cigarettes among U.S. adults, 2010-2011. Nicotine Tob Res. 2013; 18:1623-7.

18. Adkison SE, O'Connor RJ, Bansal-Travers M, Hyland A, Borland R, Yong HH, et al. Electronic nicotine delivery systems: international tobacco control four- country survey. Am J Prev Med. 2013;44:207-15.

\section{Submit your next manuscript to BioMed Central} and we will help you at every step:

- We accept pre-submission inquiries

- Our selector tool helps you to find the most relevant journal

- We provide round the clock customer support

- Convenient online submission

- Thorough peer review

- Inclusion in PubMed and all major indexing services

- Maximum visibility for your research

Submit your manuscript at www.biomedcentral.com/submit
C) Biomed Central 